Supplement of

\title{
Recovery of the first ever multi-year lidar dataset of the stratospheric aerosol layer, from Lexington, MA, and Fairbanks, AK, January 1964 to July 1965
}

Juan-Carlos Antuña-Marrero et al.

Correspondence to: Juan-Carlos Antuña-Marrero (antuna@goa.uva.es)

The copyright of individual parts of the supplement might differ from the article licence. 
Supplements

1. Complementary datasets used:

Table S1 summarize the locations of the sites where radiosonde, ozone soundings and atmospheric turbidity measurements were conducted. Also the distances from each individual site to the corresponding lidar site are provided. Following each individual dataset is described.

Table S1: Locations of the observation sites where thermodynamic variables and ozone vertical soundings were meassured nearby College, AK and Lexington, MA. Also the site of the atmospheric turbidity meassurements is listed. The last column list the distances to Lexington $\left(^{*}\right)$ and to Fairbanks(**).

\begin{tabular}{|l|l|l|l|l|l|}
\hline Station & Variable & Latitude & Longitude & Elevation & Dist. \\
\hline Nantucket, MA* & Temp, $\mathrm{Pr}$ & $41.2^{\circ} \mathrm{N}$ & $70.0^{\circ} \mathrm{W}$ & $14 \mathrm{~m}$ & $162.1 \mathrm{~km}$ \\
\hline Bedford, MA* & $\mathrm{O}_{3}$ & $42.5^{\circ} \mathrm{N}$ & $71.3^{\circ} \mathrm{W}$ & $251 \mathrm{~m}$ & $10.7 \mathrm{~km}$ \\
\hline Blue Hill Obs., MA* & TAOD $500 \mathrm{~nm}$ & $42.2^{\circ} \mathrm{N}$ & $71.1^{\circ} \mathrm{W}$ & $192 \mathrm{~m}$ & $24.1 \mathrm{~km}$ \\
\hline CARTEL, Canada* & TAOD $500 \& 675 \mathrm{~nm}$ & $45.38^{\circ} \mathrm{N}$ & $71.93^{\circ} \mathrm{W}$ & $251 \mathrm{~m}$ & $334.4 \mathrm{~km}$ \\
\hline Fairbanks, AK ${ }^{* *}$ & $\mathrm{O}_{3}, T e m p, P r$, & $64.8^{\circ} \mathrm{N}$ & $147.9^{\circ} \mathrm{W}$ & $353 \mathrm{~m}$ & $11.7 \mathrm{~km}$ \\
\hline Fairbanks, AK** & TAOD $500 \mathrm{~nm}$ & $64.86^{\circ} \mathrm{N}$ & $147.85^{\circ} \mathrm{W}$ & $133 \mathrm{~m}$ & $9.8 \mathrm{~km}$ \\
\hline Bonanza Creek, AK** & TAOD $500 \& 675 \mathrm{~nm}$ & $64.74^{\circ} \mathrm{N}$ & $148.32^{\circ} \mathrm{W}$ & $353 \mathrm{~m}$ & $23.6 \mathrm{~km}$ \\
\hline
\end{tabular}

1.1 Datasets used to estimate the thermodynamic local variables:

To derive $\beta_{\mathrm{m}}(\lambda, \mathrm{z}), \alpha_{\mathrm{m}}(\lambda, \mathrm{z}), \alpha_{\mathrm{a}}(\lambda, \mathrm{z})$ and $\mathrm{T}_{\mathrm{m}}^{2}(\mathrm{z})$ the required variables are the temperature (Temp $(\mathrm{z})$ ), pressure $(\operatorname{Pr}(\mathrm{z}))$ and molecular number density $\left(\mathrm{N}_{\mathrm{d}}(\mathrm{z})\right)$. We used the vertical profiles of $\operatorname{Temp}(\mathrm{z}), \operatorname{Pr}(\mathrm{z})$ and $\mathrm{N}_{\mathrm{d}}(\mathrm{z})$ from the 1962 US Standard Atmosphere (U. S. Standard Atmosphere, 1962).

We also made use of the Temp $(\mathrm{z})$ and $\operatorname{Pr}(\mathrm{z})$ profiles (deriving $\mathrm{N}_{\mathrm{d}}(\mathrm{z})$ ) from the most complete and nearest sounding station. In the case of the soundings we took into account the fact that lidar observations were performed at night, typically near 21:00 EST (G-66; GF-67), then we selected Temp(z) and $\operatorname{Pr}(\mathrm{z})$ profiles from nearby soundings stations conducted at 00 GMT from the Integrated Global Radiosonde Archive (IGRA) Version 2 database (Durre et al., 2016). G-66 and GF-67 mention the contemporary Bedford, MA, soundings near Lexington but although a total of 731 temperature profiles from this site are available in digital format (IGRA - 2, 2020) they only cover 1943 to 1945 . The information about the temperature profiles from the ozone soundings from 1963 to 1964 exists, but it is plotted on the ozonogram reports (Hering and Borden, 1965).

For Lexington, Massachusetts $\left(42^{\circ} 25^{\prime} \mathrm{N}, 71^{\circ} 15^{\prime} \mathrm{W}\right)$ we used the soundings from the station at Nantucket $\left(41^{\circ} 15^{\prime} \mathrm{N}, 70^{\circ} 4^{\prime} \mathrm{W}, 14 \mathrm{~m}\right.$ asl), code USM00072506, located at $163 \mathrm{~km}$ and around $1^{\circ}$ of latitude south. Because the altitude of interest is between $12 \mathrm{~km}$ and $24 \mathrm{~km}$, the upper troposphere and lower stratosphere in this region, they could be considered more representative than the US 1962 Standard Atmosphere. For Fairbanks, Alaska ( $\left.64^{\circ} 53^{\prime} \mathrm{N}, 148^{\circ} 3^{\prime} \mathrm{W}\right)$ we used Fairbanks ( $64^{\circ} 49^{\prime} \mathrm{N}, 147^{\circ} 53^{\prime} \mathrm{W}, 134 \mathrm{~m}$ asl), code USM00070261, at a distance of $11 \mathrm{~km}$. They are the nearest sounding stations in IGRA-2 with $\operatorname{Pr}(\mathrm{z})$ and Temp(z) profiles during 1964 and 1965. We used the soundings conducted the next day at 00 GMT because the local time at Nantucket, MA and Fairbanks, AK are -4 and -8 hours respect to GMT. At Nantucket, no sounding was available the next day at 00 GMT in 2 of the 66 measurements days. In those 2 cases, the same day 12 GMT sounding were used. The few gaps in $\operatorname{Temp}(\mathrm{z})$ and $\operatorname{Pr}(\mathrm{z})$ in both sets of 
data below $25 \mathrm{~km}$ were filled with the mean $\operatorname{Pr}(\mathrm{z})$ and $\operatorname{Temp}(\mathrm{z})$ profiles derived from all 1964 and 1965 Nantucket and Fairbanks daily $\operatorname{Temp}(\mathrm{z})$ and $\operatorname{Pr}(\mathrm{z})$ profiles at $00 \mathrm{Z}$.

\subsection{Datasets used for the estimation of the ozone 2-way transmittance:}

We used the $\mathrm{N}_{\mathrm{O} 3}(\mathrm{z})$ from the 1966 US Standard Atmosphere Supplement (COESA, 1967). In addition, we used the seasonal means of $\mathrm{N}_{\mathrm{O} 3}(\mathrm{z})$ between 1963 and 1967 from ozone soundings conducted at L. G. Hanscom Fla., Bedford, MA and Fairbanks, AK for Lexington and Fairbanks respectively (Hering and Borden, 1967).

The profile of the ozone absorption coefficient at a given wavelength $\left(\mathrm{k}_{\mathrm{O} 3}(\lambda, \mathrm{z})\right)$ is calculated using the profile of ozone cross sections $\left(\sigma_{\mathrm{O} 3}(\lambda, \operatorname{Temp}(\mathrm{z}))\right)$ :

$$
\mathrm{k}_{\mathrm{O} 3}(\lambda, \mathrm{z})=\sigma_{\mathrm{O} 3}(\lambda, \operatorname{Temp}(\mathrm{z})) \times \mathrm{N}_{\mathrm{O} 3}(\mathrm{z})
$$

at the temperature $(\operatorname{Temp}(\mathrm{z}))$, where $\mathrm{N}_{\mathrm{O} 3}(\mathrm{z})$ is the number density of ozone. The $\sigma_{\mathrm{O} 3}(\lambda, \operatorname{Temp}(\mathrm{z}))$ at $\lambda=$ $694 \mathrm{~nm}$ is provided by Serdyuchenko et al., (2014) in the temperature range 193 to $293{ }^{\circ} \mathrm{K}$. We used the average of $\sigma_{\mathrm{O} 3}(\lambda, \operatorname{Temp}(\mathrm{z})), 9.88 \mathrm{e}-22 \mathrm{~cm}^{2}$ molecules$^{-1}$, considering that the standard deviation of this averaging profile represents $2.4 \%$ variability of the average value. This set of absorption coefficients have been recommended by the recent status report from the International Ozone Commission from WMO (Orphal et al., 2016).

\subsection{Datasets used for the estimation of the tropospheric aerosol 2-way transmittance:}

For Lexington we found contemporary statistics of turbidity measurements $(\mathbf{B})$ at $\lambda=500 \mathrm{~nm}$. Those measurements were part of the turbidity network established in 1961 by the U. S. Weather Bureau Research Station (later National Center for Air Pollution Control), Cincinnati, Ohio. For Lexington, the measurements were conducted at Blue Hill Observatory, Boston, Ma, $24 \mathrm{~km}$ from the lidar location. The Blue Hill Observatory frame plot with the monthly means for the period 1961 to 1966 are in figure 3 in Flowers et al., (1969). The curve of the monthly mean B belonging to Blue Hill Observatory in the frame plot on the figure were digitized (WebPlotDigitize, 2020). Then TAOD at $\lambda=500 \mathrm{~nm}$ was calculated using the equation (Volz, 1969), resulting from converting the decadic logarithm used to define $\mathbf{B}$ to the neperian logarithm used for AOD:

$$
\mathbf{B}=0.434 \times \mathrm{TAOD}
$$

For Fairbanks we did not find contemporary measurements, but there were manually conducted measurements in several places in the Arctic and Antarctic, including at Fairbanks $\left(64.86^{\circ} \mathrm{N}, 147.85^{\circ} \mathrm{W}\right.$, $133 \mathrm{~m}$ ), with sun photometers at several wavelengths (Shaw, 1982). Those measurements are reported to be corrected by the molecular scattering and gas absorption (Shaw et al., 1973). The instruments were calibrated at Mauna Loa Observatory using Langley method with root mean square errors (RMSE) of sun photometer voltage output readings $(\mathrm{V})$ of $\frac{\delta \mathrm{V}}{\mathrm{V}} \approx 10^{-3}$ having a systematic $\mathrm{RMSE}$ for AOD $=+/-0.002$ and the total error estimated as $+/-0.004$ (Shaw, 1982). At Fairbanks the annual mean AOD $=0.110$ from 105 observations at $\lambda=500 \mathrm{~nm}$ is reported on table 1 of the cited reference, but also the AOD annual cycle appears in the lower panel of figure 2 from Shaw (1982), showing the high AOD values in late 
winter and spring, peaking up to 0.135 . We then digitized the mean AOD and its variation range values for July (no data for August appears on the figure), resulting AOD $=0.082 \pm 0.022$. Although Shaw (1982) does not provide the information of the year the measurements were conducted this data is cited and cited to have been conducted in 1978 by Freund (1983).

We also used AOD data at $500 \mathrm{~nm}$ from the 2 nearest AERONET stations to each site having long-term records. Bonanza Creek, AK, is less than $30 \mathrm{~km}$ from the location the lidar measurements were reported to be conducted at Fairbanks. TAOD measurements at this site have been conducted from 1997 to the present. The other site belongs to the Centre d'Applications et de Recherches en Teledetection (CARTEL), at the Universite de Sherbrooke, Canada, $334 \mathrm{~km}$ from Lexington.

From both sites we also used the climatological monthly means of TAOD at 500 and $675 \mathrm{~nm}$ from 1997 to 2019 for Bonanza Creek, and 1995 to 2019 for CARTEL (AERONET, 2020). We then derived the TAOD at $532 \mathrm{~nm}$ using the Ångstrom exponents calculated from the TAOD climatological monthly means for the interval 440 to $870 \mathrm{~nm}$, which we used for Lexington. In the case of Bonanza Creek, we had one "contemporary" value from July 1978 (Shaw, 1982), and we selected the July climatological monthly mean, as the "current" value. After the conversion to $532 \mathrm{~nm}$ they were respectively 0.087 from Fairbanks, AK, in July 1978 (Shaw, 1982) and 0.242 from the July 1997- 2019 climatology at Bonanza Creek, AK, and we used the July 1978 value for both July and August 1964 lidar measurements at Fairbanks.

In the case of Lexington, for comparison purposes, we digitized the average monthly mean TAOD for 26 Eastern US stations from 1972 to 1975 from Husar et al., (1981). The series of monthly mean TAOD values were converted from $500 \mathrm{~nm}$ to $532 \mathrm{~nm}$, with the procedure described above, using the Ångstrom exponents for the interval 440 to $870 \mathrm{~nm}$. The Figure S1 shows the resulting values. The high TAOD values of the two series, from the Blue Hill Observatory (1961-1966) and the Eastern US (1972-1975), are representative of what have been reported for the Eastern US (Husar et al., 1981). The natural conditions contribute to an elevated background AOD attributed to the combination of absolute and relative humidity, and the vegetation density, both of which could be responsible for increased natural aerosols either from hygroscopic marine aerosols or from secondary aerosols originating from vegetation (e.g. Went, 1960). Additionally an important contribution to the TAOD came from anthropogenic aerosols originating from the extensive use of fossil fuels in the region. In fact, as their Figure S1 shows, the pollution increased with respect to the 1960s (Husar et al., 1981). Recent research reports aerosol simulations for the historical period from 1850 to 2014 using the GISS ModelE2.1 with two different aerosol schemes to contribute to the Coupled Model Intercomparison Project Phase 6 (CMIP6). The simulations result in the AOD showing an increasing trend from well before 1900 until the early 1970s in the Eastern US, supporting the AOD data features we collected from Blue Hills Observatory (Bauer et al., 2020). 


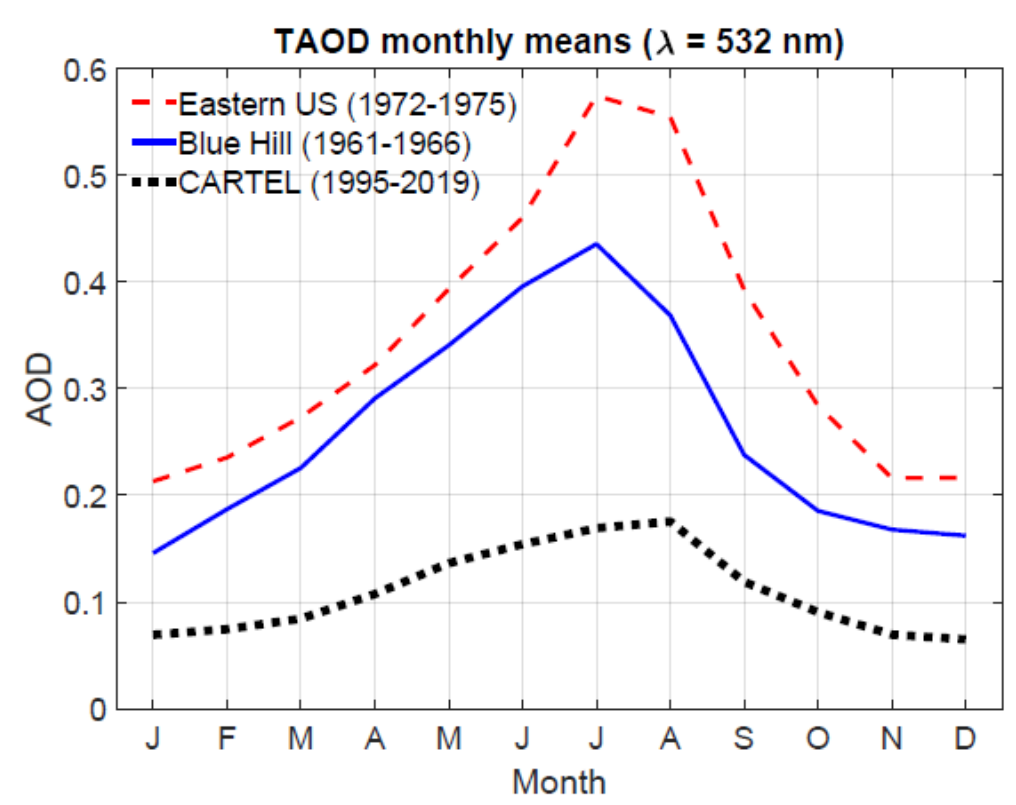

Figure S1: Contemporary and current TAOD monthly means at $532 \mathrm{~nm}$ from Blue Hill Observatory, MA, from 1961 to 1966, the average of 26 stations in Eastern US between 1972 and 1975 and CARTEL, Canada, from 1995 to 2019.

References:

AERONET, 2020, Aerosol Robotic Network, http://aeronet.gsfc.nasa.gov/

Bauer, S. E., Tsigaridis, K., Faluvegi, G., Kelley, M., Lo, K. K., Miller, R. L., et al, Historical (18502014) aerosol evolution and role on climate forcing using the GISS ModelE2.1 contribution to CMIP6. Journal of Advances in Modeling Earth Systems, 12, e2019MS001978. https://doi.org/10.1029/2019MS001978, 2020.

COESA, Committee on Extension to the Standard Atmosphere, U. S. Standard Atmosphere Supplements 1966, U.S. Government Printing Office, Washington, D.C., 1967.

Durre, Imke, Xungang, Yin, Vose, Russell S., Applequist, Scott, Arnfield, Jeff. Integrated Global Radiosonde Archive (IGRA), Version 2. [Individual soundings]. NOAA National Centers for Environmental Information. DOI:10.7289/V5X63K0Q [Accessed: April,3 2020], 2016.

Flowers, E. C., R. A. McCormick, and K. R. Kurfis, Atmospheric turbidity over the United States, 19611966. J. Appl. Meteor., 8, 955-962, 1969.

Freund, J., Aerosol optical depth in the Canadian arctic, Atmosphere-Ocean, 21:2, 158-167, DOI: 10.1080/07055900.1983.9649162, 1983.

Grams, G., Optical radar studies of stratospheric aerosols. PhD Thesis, 121 pp., https://dspace.mit.edu/bitstream/handle/1721.1/13502/25776466-MIT.pdf, 1966.

Grams, G ., and G. Fiocco, Stratospheric aerosol layer during 1964 and 1965, J. Geophys. Res., 72, 3523$3542,1967$.

Hering, W. S., and T. R. Borden, Jr., Ozonesonde Observations over North America, 4, Environmental Research Papers, No. 279, Air Force Cambridge Research Laboratories, Report AFCRL-64-30(IV), 1967. 
Husar, R. B., J. M. Holloway, D. E. Patterson, W. E. Wilson, Spatial and temporal pattern of eastern U.S. haziness: A summary, Atm. Env. 15, 10-11, 1919-1928, 1981.

Serdyuchenko, A., Gorshelev, V., Weber, M., Chehade, W., and Burrows, J. P.: High spectral resolution ozone absorption crosssections - Part 2: Temperature dependence, Atmos. Meas. Tech., 7, 625-636, doi:10.5194/amt-7-625-2014, 2014.

Shaw, G. E,, J. A. Reagan and B. M. Herman, Investigations of atmospheric extinction using direct solar radiation measurements made with a multiple wavelength photometer. J. Appl. Meteor., 12, 374-380, 1973.

Shaw, G. E., Atmospheric Turbidity in the Polar Regions, J. Appl. Meteor., 21, 8, pp. 1080-1088, 1982.

U. S. Standard Atmosphere, U. S. Gov't. Printing Office, Washington, D. C., 1962.

Volz, F. E., Some results of turbidity networks. Tellus, 21, 625-630, 1969.

WebPlotDigitizer, https://automeris.io/WebPlotDigitizer/ [Accessed, May 2020]

Went F. W. Organic matter in the atmosphere, and its possible relation to petroleum formation. Proc. Natn. Acad. Sci. U.S.A. 46, 212-221, 1960. 